\title{
Trauma and Treatment of Child Sexual Abuse
}

\section{Allison N Sinanan}

Department of Social Work, Stockton University, NJ, USA

*Corresponding author: Allison N. Sinanan, PhD, Department of Social Work, Stockton University, 101 Vera King Farris Drive, Galloway, NJ 08205-9441, USA, Tel: 609 626-3561; E-mail: allison.sinanan@stockton.edu

Rec date: September 02, 2015; Acc date: October 02, 2015; Pub date: October 09, 2015

Copyright: $\odot 2015$ Sinanan AN. This is an open-access article distributed under the terms of the Creative Commons Attribution License, which permits unrestricted use, distribution, and reproduction in any medium, provided the original author and source are credited.

\section{Abstract}

Children who are victims of sexual abuse not only endure trauma, but also are likely to experience negative symptomatology as a result of this horrific ordeal. This article reviews the literature on child sexual abuse and examines the most effective treatment modalities that deal with the associated trauma. This review is not comprehensive but rather provides some highlights of the current treatment outcome literature for treating childhood trauma associated with child sexual abuse.

Keywords: Trauma and treatment; Child sexual abuse

\section{What is Child Sexual Abuse?}

Child Abuse and Prevention Treatment Act (CAPTA) defines sexual abuse as the use, persuasion, or coercion of any child to engage in any sexually explicit conduct (or any simulation of such conduct) for the purpose of producing any visual depiction of such conduct, or rape, molestation, prostitution, or incest with children. Child sexual abuse is a widespread problem in the United States. In 2012, approximately 90,000 children in the United States were reported to child protective services for suspected child sexual abuse. The actual number is likely to be higher because these numbers reflect only children whose cases are investigated by child protective services. It is estimated that 1 in 4 girls and 1 in 6 boys will have experienced an episode of sexual abuse while younger than 18 years. The numbers of boys affected may be falsely low because of reporting techniques (U.S. Department of Health and Human Services, Administration for Children and Families, 2012) $[1,2]$.

Retrospective surveys reveal considerable variation in the prevalence rates for child sexual abuse. The prevalence of child sexual abuse ranging from $12 \%$ to $18 \%$ for females and $2 \%$ to $12 \%$ for males [3]. Methodological factors such as sampling methods, methods of data collection, response rates, definition of child sexual abuse, and types of questions used to assess the abuse many contribute to the variability in the prevalence rates [4]. According to the literature, child sexual abuse is a risk factor for the development of an array of intra and interpersonal difficulties, including depression, anxiety, posttraumatic stress, dissociation, personality and eating disorders, and dyadic distress [5-7].

Even though the prevalence of sexual abuse and the increased knowledge regarding its impact, a definitive consensus of how to best treat CSA survivors is still lacking; the research concerning this treatment is in its earliest stages [8]. The consequences of sexual abuse are certainly not universal and impact each individual uniquely; hence, making it essential for the mental health professional to correctly address the variety of symptoms. This article reviews the literature on child sexual abuse and examines the most effective treatment modalities that deal with the associated trauma.

\section{Psychological Effects and Trauma}

Childhood sexual trauma can have a profoundly devastating effect upon the victim. Some individuals appear to be relatively asymptomatic while others can be greatly affected. Sexual trauma can impact many of the normal developmental processes of childhood; typically exhibited by emotional or behavioral features that show distress [9]. Victims of child sexual abuse attempt numerous efforts to psychologically escape from the abuse (e.g. avoidance, attempts at memory repression, distraction, addictive behaviors) and cognitive efforts at coping (e.g. cognitive reappraisal, reframing, minimization, and working through the abuse, among others).

Childhood sexual abuse has been correlated with higher levels of depression, guilt, shame, self-blame, eating disorders, somatic concerns, anxiety, dissociative patterns, repression, denial, sexual problems, relationship problems and trauma. The psychological effects of child sexual abuse often occur irrespective of the particular extent of trauma the child experienced during the abuse. With respect to trauma, the American Psychiatric Association's Diagnostic and Statistical Manual, Fifth Edition (DSM-5), classify the trigger to Post Traumatic Stress Disorder (PTSD) as exposure to actual or threatened death, serious injury or sexual violation. The DSM-V offers four distinct diagnostic clusters described as: re-experiencing, avoidance, negative cognitions and mood, and arousal. The exposure must result from one or more of the following scenarios in which the individual: directly experiences the traumatic event; witnesses the traumatic event in person; learns that the traumatic event occurred to a close family member or close friend (with the actual or threatened death being either violent or accidental); or experiences first-hand repeated or extreme exposure to aversive details of the traumatic event (not through media, pictures, television or movies unless work-related). It must be noted that there are differences in criteria PTSD among adults and children; the DSM-5 lists the distinction between the two populations, but makes the differentiation for criteria for children less than 6 years of age. The DSM-5 lists the following diagnostic criteria for PTSD in adults, adolescents, and children older than 6 years:

- Exposure to actual or threatened death, serious injury, or sexual violation

- Presence of 1 or more specified intrusion symptoms in association with the traumatic event(s) 
Page 2 of 5

- Persistent avoidance of stimuli associated with the traumatic event(s)

- Negative alterations in cognitions and mood associated with the traumatic event(s)

- Marked alterations in arousal and reactivity associated with the traumatic events(s)

- Duration of the disturbance exceeding 1 month

- Clinically significant distress or impairment in important areas of functioning

- Inability to attribute the disturbance to the physiologic effects of a substance or another medical condition

- DSM-5 criteria for PTSD in children aged 6 years or younger are as follows:

- Exposure to actual or threatened death, serious injury, or sexual violation

- Presence of 1 or more specified intrusion symptoms in association with the traumatic event(s)

- Symptoms indicating either persistent avoidance of stimuli associated with the traumatic event(s) or negative alterations in cognitions and mood associated with the event(s)

- Marked alterations in arousal and reactivity associated with the traumatic events(s)

- Duration of the disturbance exceeding 1 month

- Clinically significant distress or impairment in relationships with parents, siblings, peers, or other caregivers or in school behavior

- Inability to attribute the disturbance to the physiologic effects of a substance or another medical condition

There are many contributing factors that determine the extent of the negative impact of childhood sexual trauma [5]. Children are more likely to suffer to a greater extent if the perpetrator is a close relative such as a father as opposed to a neighbor. Children who were sexually abused during earlier stages of development have fewer resources which would allow them to cope and may suffer more adverse consequences $[10,11]$. Sexual abuse may occur as a single incident or it may have continued over a number of months or years. Even though a child may not be truly cognizant of what is sexually occurring, he/she can still unfortunately experience the negative psychological consequences. The common psychological effects include: depression, anxiety, internal somatic complaints, and thought problems $[9,12,13]$. Specifically, with respect to depression, research has suggested that a history of child sexual abuse is associated with a negative cognitive style (i.e. internal, global, and stable) in adulthood which has been suggested as a risk factor in the development of depression [13-15]. Depression has been found to be the most common long-term symptom among survivors. For survivors of childhood sexual abuse, feelings of confusion, disorientation, nightmares, flashbacks, and difficulty experiencing feelings can occur. Dissociation is also a symptom of this abuse. Some survivors of child sexual abuse may dissociate to protect themselves from experiencing the sexual abuse and continue to use this coping mechanism when they feel unsafe or threatened as adults [16]. It is essential to note that although research has shown there to be significant long-term effect variables and childhood sexual abuse, each victim's symptoms and experiences will not be the same. Although it is often viewed as a traumatic experience, there is no single symptom among all survivors and it is imperative for clinicians to focus on the individual needs of the client. Mental health professionals must be careful not to treat each survivor of abuse as having the same symptomology.

\section{Systems Theory and Betrayal}

An underlying concept in general systems theory is that of boundaries. A boundary binds together the components that make up the system, protects them from environmental stresses, and controls entry of resources and information [17]. When a child is sexually abused, an obvious boundary of their sexual and physical health has been broken by the perpetrator. Child sexual abuse, according to the tenets of general systems theory, represents a flaw in the family system's capability to uphold correct spatial relationships. Sexual abuse of children is, therefore, an improper crossing of boundaries. This betrayal of broken boundaries of trust, among other factors, affects the child victim psychologically in a variety of ways. Incest, the ultimate break of trust of boundaries greatly affects the coping strategies of the child victim. Since child sexual abuse occurs when identity and cognitive schemas are developing, the abuse may become a part of the victim's internal representations of the self and self in relation to others $[18,19]$. Consequently, because incest occurs during formative years, the abuse may develop as a "norm" for the child. This can lead to an unfortunate feeling that complicates a child's perspective on the abuse may be the case that a child may have extreme guilt because he or she feels he or she has done something wrong by being a part of the abuse and does not possess the mental capacity to understand that he or she is a victim. Hence, the victim might experience irritability when he or she does not know how to cope with the confusion or possess the ability to talk about the abuse to others.

Children do not have the same resources as adults. They are completely dependent upon the adults entrusted to care for them, and that can leave them extremely vulnerable. Children may not understand that others act independently of them and that their motivations are often less than pure. Hence, often feeling responsible for what has happened to them. They may often experience guilt, shame, and self-blame. It has been shown that survivors frequently take personal responsibility for the abuse. Survivors often blame themselves and internalize negative messages about themselves. Survivors tend to display more self-destructive behaviors and experience more suicidal ideation than those who have not been abused.

Children, specifically younger children, depend exclusively on parents/caregivers for survival and protection, both physical and emotional. When the trauma involves the parent/caregiver as the perpetrator of the abuse, the support of a trusted parent/caregiver to help them regulate their strong emotions is lost; hence, children may experience overwhelming stress, with little ability to effectively communicate what they feel or need. These children may have very little sense of safety and security. These children are often left in a chronic state of anxiety and hyper vigilance. The individual may be consumed by the need to protect him or herself from further assault [19]. A study compared the posttraumatic stress symptoms in Vietnam veterans and adult survivors of childhood sexual abuse. The study revealed that childhood sexual abuse is traumatizing and can result in symptoms comparable to symptoms from war-related trauma.

\section{Coping with Trauma}

The most common effect of sexual abuse is Post Traumatic Stress Disorder. Symptoms can include withdrawn behavior, reenactment of the traumatic event, avoidance of circumstances that remind one of the events, and physiological hyper-reactivity. Variables that have a tremendous impact on the victim's emotional and behavioral outcomes 
Page 3 of 5

have to do with the characteristics of the abuse (e.g. relationship to the perpetrator, the nature of the abusive acts, the use of force or threat, and frequency/duration of the abuse [20-22]. Unfortunately, for many children, there may be exposed to continuous reminders of the abuse (e.g. continued contact with the perpetrator) and be unable to escape from the abusive situation. Though, the detrimental effects associated with child sexual abuse indicate that not all victims report disruptions in functioning, either in the short- or long-term [20].

\section{Treatment for Trauma Associated with Child Sexual Abuse}

Psychotherapy aids as the first model of a healthy relationship for many victims of sexual abuse [23]. This treatment can offer a model of a healing, nurturing relationship, where the client can discover to experience trust. Psychotherapy provides the client with an opportunity to rework the trauma into a healthier sense of self. Cognitive therapy for PTSD focuses on teaching clients how to identify, evaluate, and reframe the dysfunctional cognitions related to the specific trauma and its sequelae that contribute to the intense negative emotions and behavioral reactions [24]. Cognitive Behavior Therapy (CBT) includes a range of approaches that have been shown to be effective in treating posttraumatic stress disorder (PTSD). Cognitive behavioral methods have also demonstrated to be significantly effective in demonstrating positive outcomes with child sexual abuse victims in children [25], and in adult survivors $[8,26]$. Cognitive-behavioral therapy (CBT) methods stem from the central principle that an individual's cognitions play a significant and primary role in the development and maintenance of emotional and behavioral responses to life situations. The manner in which individuals emotionally and cognitively process a traumatic experience contributes to the development and maintenance of PTSD [24,27,28]. A central theme contributing to the onset and persistence of PTSD is a perception of ongoing threat, even when the trauma occurred in the distant past.

CBT demonstrates positive results in treating sexually abused children [26]. In a study involving 100 children, a comparison of four treatment conditions was conducted with 12 -week abuse-focused CBT model for the child only, CBT for the parent only, CBT for the both the child and the parent, and a cluster that only experienced standardized community care. Improvement occurred in each treatment condition, with the most benefit resulting from the therapy with the child alone. Other studies also show great improvement in PTSD symptoms and overall functioning in sexually abused children receiving CBT compared with nonspecific treatment strategies and wait-list controls $[16,29]$.

\section{Trauma-Focused Cognitive Behavioral Therapy}

Trauma-focused cognitive behavioral therapy (TF-CBT) developed by Cohen, Mannarino, and Deblinger, is a psychosocial treatment model designed to treat posttraumatic stress and related emotional and behavioral problems in children and adolescents; initially developed to address the psychological trauma associated with child sexual abuse. TF-CBT is comprised of education about childhood trauma and PTSD; emotion education and emotion regulation skills; relaxation and stress management; connecting thoughts, feelings, and behaviors related to the trauma; direct discussion or sharing of the traumatic event. There is an emphasis on the connection between the survivor's symptomology and past environment in order to decrease distress levels by recovering and reinterpreting memories of the trauma [8]. In a study reviewing different treatment modalities for child sexual abuse, of the two hundred and ten children (aged 4-11 years) randomly assigned to one of the four treatment conditions: 8 sessions with no TF-CBT, 8 sessions with TF-CBT, 16 sessions with no TF-CBT, and 16 sessions with TF-CBT, research indicated that within 12 to 16 sessions of TF-CBT, most children will show substantial progress [30]. The main strength of this treatment modality is the fact that it teaches coping skills and the ability to feel safe in future situations; a necessity for victims of child sexual abuse.

In another study, Cohen and Mannarino [31] compared TF-CBT to Non-directive Supportive Therapy for 86 preschool children ages 3-7 years old who experienced sexual abuse, and their non-abusive parents. TF-CBT was more successful in improving some PTSD symptoms that were assessed by the Weekly Behavior Report, sexual behaviors, total behavior problems, and internalized behavior symptoms. Differential findings were maintained at 6- and 12-month follow-ups. Parental sexual abuse-related emotional distress and parental support for the child each mediated children's outcomes, suggesting the importance of including parents in treatment. Both of these studies exhibit the practicality of using manual-based treatments and conducting treatment outcome research with children who have experienced trauma. Children who have undergone this treatment have demonstrated significantly more improvement in PTSD, depression, and other emotional and behavioral symptoms after TFCBT than after child-centered therapy [30]. Empirical evidence has shown that reviews completed regarding sexual abuse treatment literature documented TF-CBT as having very high empirical support for its effectiveness [25,26,30,32]. Trauma-Focused Cognitive Behavioral Therapy (TF-CBT) is believed to truly address and be the most effective with victims of trauma [33]. The Kauffman Best Practices Report has recognized TF-CBT as an evidence-based treatment for sexually abused children.

\section{Group Therapy}

Group therapy has been identified as the treatment of choice when working with sexually abused adolescents [34]. Groups create an environment where survivors of sexual abuse can meet and interact with other individuals who faced with similar presenting problems. According to Yalom and Leszcz group therapy provides benefits beyond what individual therapy is able to provide by increasing empowerment and psychological well-being [35]. Groups provide a supportive environment that facilitates the development of trust, hence leading to the ability to connect with others. Distortions in thinking and negative self-images are confronted and are substituted with views of self that are nurturing and self-accepting. The major strength of support group is commonality. Many clients find it easier to share their personal experience with others who have gone through similar abuse; which assists in diminishing the underlying shame that tends to exist with sexual abuse. In a study comparing sexual abuse survivors receiving group therapy to a control wait-listed group (all participants were simultaneously in individual therapy), results indicated those receiving group therapy reduced their depression and anxiety levels by statistically significant amounts [36]. Lindon and Nourse founded a group approach for treating sexually abused adolescent females emphasizing three main constructs. These constructs include skills training, psychotherapeutic interventions such as the empty chair, and an educational piece involving the female sexual anatomy. Self-reports 
indicated this treatment was effective and the girls demonstrated an increase in positive feelings about themselves [34].

\section{Pharmacological Studies}

Only two pharmacological randomized control trials to date have been done explicitly for children with trauma symptoms; only one study specific to sexual abuse. Cohen, Mannarino, Perel, Staron compared TF-CBT+sertraline (sertraline is an antidepressant used to treat depression, obsessive-compulsive disorder, panic disorder, anxiety disorders, post-traumatic stress disorder (PTSD), and premenstrual dysphoric disorder) to TF-CBT+placebo in 24 sexually abused children ages 10-17 years old [37]. The study found that the addition of the medication sertraline did not significantly improve the efficacy of TF-CBT in decreasing PTSD or other symptoms. This study was underpowered due to the small sample size. The second study, compared imipramine, a tricyclic antidepressant, to chloral hydrate, a sedative, in treating acute stress disorder (ASD) symptoms in 2- to 19year old burn patients over 7 days during acute hospitalization. Results of this double-blind randomized trial confirmed that imipramine was superior to chloral hydrate in decreasing ASD symptoms. Concerns about imipramine causing possibly serious cardiac conduction delays thwart the widespread usage of this medication on an outpatient basis. Concerns about selective serotonin reuptake inhibitor medication use in children will possibly limit future research in this regard [37].

\section{Eye Movement Desensitization and Reprocessing}

Eye Movement Desensitization and Reprocessing (EMDR) is a treatment method used to treat the symptoms of trauma as well as other emotional conditions. EMDR was originally developed to treat adults with PTSD; however, it is also used to treat other conditions and children. EMDR reduces the long-lasting effects of stressful memories by developing more adaptive coping mechanisms. The therapy uses an eight-phase approach that includes having the client recollect distressing images while receiving one of several types of bilateral sensory input, such as side to side eye movement [38].

EMDR allows a client to process an emotional experience that the client cannot yet speak about, such as abuse. The therapist uses directive questioning to desensitize the client through a brief imagined exposure to the traumatic memory [39]. The client is asked to provide a negative cognition of the trauma and identify places in the body where the physical sensations are felt. After focusing on the traumatic memory, the client receives bilateral stimulation. This method involves therapist-directed saccadic eye movements, with the therapist moving his or her fingers back and forth in front of the client's face after instructing the client to follow the movement with his or her eyes. This sequence is repeated until the accompanying level of disturbance has diminished and the dysfunctional cognitions about the trauma have been improved [39].

Taylor, Lerner, Sherman, Sage, and McDowell compared eight sessions of EMDR therapy with eight sessions of cognitive behavioral therapy [40]. The cognitive behavioral therapy component consisted of four sessions of imaginal exposure, in which the client holds the traumatic event in mind while describing it in detail, plus four sessions of therapist-assisted in vivo exposure, in which the therapist accompanies the client to an anxiety-provoking environment, plus one hour of daily homework, totaling about 50 hours over the course of the treatment. The EMDR component used only standard therapy sessions and no homework. According to the results of this study, cognitive behavioral therapy was superior on some measures. Similarly, building on previous research with disaster exposed children and adolescents; a randomized clinical study was conducted in the treatment of traumarelated symptoms. The primary aim of this study was to compare the effectiveness and efficiency of (CBT) and. Fifty-two children aged 4-18, were equally randomly assigned to either CBT $(n=26)$ or EMDR $(n=26)$ in a disaster mental health after-care setting after an explosion of a fireworks factory. All children received up to four individual treatment sessions over a 4-8 week period along with up to four sessions of parent guidance. Results indicated that both treatment approaches produced significant reductions on all measures and results were maintained at follow-up. Treatment gains of EMDR were reached in fewer sessions.

\section{Conclusion}

It is important that research continue on the topic of the long-term effects of childhood sexual abuse. The severity of this issue and the significant implications it has on the lives of child and adult victims have been well established. With this knowledge, it is imperative that mental health professionals continue to expand their knowledge of best practices for survivors of child sexual abuse and be aware of all of the different types of treatment modalities. Though not extensive, this article attempts to provide a comprehensive look at the best practices for working with survivors of child sexual abuse and the common symptomology that comes with this specific trauma. Mental health professionals have the obligation to adhere and attend to a client's preferences, cultural differences, and their own strengths and abilities while still providing scientifically grounded treatments for children who are enduring the of trauma of child sexual abuse.

\section{References}

1. U.S. Department of Health and Human Services, National Center on Child Abuse and Neglect, National Child Abuse and Neglect Data System (2012). Child maltreatment 2012. Washington, DC: U.S. Government Printing Office.

2. U.S. Department of Health and Human Services (2012) Administration on Children and Families. Child maltreatment.

3. Bolen RM (2001) Child Sexual Abuse: Its Scope and Our Failure. Kluwer Academic/Plenum Publishers, New York, NY, USA.

4. Vogeltanz ND, Wilsnack SC, Harris TR, Wilsnack RW, Wonderlich SA, et al. (1999) Prevalence and risk factors for childhood sexual abuse in women: national survey findings. Child Abuse Negl 23: 579-592.

5. Finkelhor D, Browne A (1985) The traumatic impact of child sexual abuse: a conceptualization. Am J Orthopsychiatry 55: 530-541.

6. DiLillo D (2001) Interpersonal functioning among women reporting a history of childhood sexual abuse: Empirical findings and methodological issues. Clin Psychol Rev 21: 553-576.

7. Neumann DA, Houskamp BM, Pollock VE, Briere J (1996) The long term sequelae of childhood sexual abuse in women: a meta-analytic review. Child Maltreatment 1: 6-16.

8. Spiegel D, Classen C, Thurston E, Butler L (2004) In: L. Koenig book (Eds) Trauma-focused versus present-focused models of group therapy for women sexually abused in childhood (Vol I). Washington, DC: American Psychological Association.

9. Maltz W (2002) Treating the sexual intimacy concerns of sexual abuse survivors. Sexual and Relationship Therapy 17: 321-327.

10. Kendall-Tackett KA, Williams LM, Finkelhor D (1993) Impact of sexual abuse on children: a review and synthesis of recent empirical studies. Psychol Bull 113: 164-180.

11. Knutson JF (1995) Psychological characteristics of maltreated children: putative risk factors and consequences. Annu Rev Psychol 46: 401-431. 
12. Sachs-Ericsson N, Verona E, Joiner T, Preacher KJ (2006) Parental verbal abuse and the mediating role of self-criticism in adult internalizing disorders. J Affect Disord 93: 71-78.

13. Garber J, Flynn C (2001) Predictors of depressive cognitions in young adolescents. Cognitive Therapy and Research 4: 353-375.

14. Hankin BL, Abramson LY, Siler M (2001) A prospective test of the hopelessness theory of depression in adolescence. Cognitive Therapy and Research 5: 607-632.

15. Stein MB, Walker JR, Anderson G, Hazen AL, Ross CA, et al. (1996) Childhood physical and sexual abuse in patients with anxiety disorders and in a community sample. Am J Psychiatry 153: 275-277.

16. King N, Tonge B, Mullen P (2000) Treating sexually abused children with posttraumatic stress symptoms: A randomized clinical trial. J Am Acad Child Adolesc Psychiatry 39: 1347-1355.

17. Miller JG (1978) Living systems. McGraw-Hill, New York, NY, USA.

18. Fergusson DM, Horwood LJ, Lynskey MT (1996) Childhood sexual abuse and psychiatric disorder in young adulthood: II. Psychiatric outcomes of childhood sexual abuse. J Am Acad Child Adolesc Psychiatry35. 1365-1374.

19. Toth SL, Maughan A, Manly JT, Spagnola M, Cicchetti D (2002) The relative efficacy of two interventions in altering maltreated preschool children's representational models: Implications for attachment theory. Dev Psychopathol 14: 877-908.

20. Bennett SE, Hughes HM, Luke DA (2000) Heterogeneity in patterns of child sexual abuse, family functioning, and long-term adjustment. Journal of Interpersonal Violence 75: 134-157.

21. Williams LM (1994) Recall of childhood trauma: a prospective study of women's memories of child sexual abuse. J Consult Clin Psychol 62: 1167-1176.

22. Trickett PK, Reiffman A, Horowitz LA, Putman FW (1997) Characteristics of sexual abuse trauma and the prediction of developmental outcomes In D. C. S.

23. Talbot NL, Chaudron LH, Ward EA, Duberstein PR, Conwell Y, et al. (2011) A randomized effectiveness trial of interpersonal psychotherapy for depressed women with sexual abuse histories. Psychiatr Serv 62: 374-380.

24. Ehlers A, Clark DM (2000) A cognitive model of posttraumatic stress disorder. Behav Res Ther 38: 319-345.

25. Deblinger E, Mannarino AP, Cohen JA, Runyon MK, Steer RA (2011) Trauma-focused cognitive behavioral therapy for children: impact of the trauma narrative and treatment length. Depress Anxiety 28: 67-75.

26. Putnam FW (2003) Ten-year research update review: child sexual abuse. J Am Acad Child Adolesc Psychiatry 42: 269-278.
27. Clark DM, Ehlers A (2004) Posstraumatic stress disorders from cognitive theory to therapy. In: Leahy RL (ed.) Contemporary cognitive therapy: Theory, research, and practice. Guilford, New York, USA, 141-160.

28. Foa EB, Kozak MJ (1986) Emotional processing of fear: exposure to corrective information. Psychol Bull 99: 20-35.

29. Celano M, Hazzard A, Webb C, McCall C (1996) Treatment of traumagenic beliefs among sexually abused girls and their mothers: an evaluation study. J Abnorm Child Psychol 24: 1-17.

30. Cohen JA, Deblinger E, Mannarino AP, Steer RA (2004) A multisite, randomized controlled trial for children with sexual abuse-related PTSD symptoms. J Am Acad Child Adolesc Psychiatry 43: 393-402.

31. Cohen JA, Mannarino AP (1996) A treatment outcome study for sexually abused preschool children: Initial findings. J Am Acad Child Adolesc Psychiatry 35: 42-50.

32. Saunders BE, Berliner L, Hanson RF (2004) Child Physical and Sexual Abuse: Guidelines for Treatment.

33. Bol C (2008) Trauma focused therapy for the treatment of posttraumatic stress disorder in sexually abused children: A summary and evaluation of research. Graduate Journal of Counseling Psychology 1: 147-158.

34. Lindon J, Nourse CA (1994) A multi-dimensional model of groupwork for adolescent girls who have been sexually abused. Child Abuse Negl 18: 341-348.

35. Yalom and Leszcz (2005) The Theory and Practice of Group Psychotherapy. (5thedn) Basic Books.

36. Westbury E, Tutty LM (1999) The efficacy of group treatment for survivors of childhood abuse. Child Abuse Negl 23: 31-44.

37. Cohen JA, Mannarino AP, Perel JM, Staron VA (2007) Pilot randomized controlled trial of combined Trauma-Focused CBT and sertraline for childhood PTSD symptoms. J Am Acad Child Adolesc Psychiatry 46: 811-819.

38. Feske, Ulrike (1998) Eye movement desensitization and reprocessing treatment for posttraumatic stress disorder. Clinical Psychology: Science and Practice 5: 171-181.

39. Shapiro F (2007) EMDR and case conceptualization from an adaptive information processing perspective. In: Shapiro F, Kaslow F, Maxfield L (eds.) Handbook of EMDR and family therapy processes. John Wiley, New York, USA, 3-36.

40. Taylor SE, Lerner JS, Sherman DK, Sage RM, McDowell NK (2003) Are self-enhancing cognitions associated with healthy or unhealthy biological profiles? J Pers Soc Psychol 85: 605-615. 